Article

\title{
Quinolin-6-Yloxyacetamides Are Microtubule Destabilizing Agents That Bind to the Colchicine Site of Tubulin
}

\author{
Ashwani Sharma ${ }^{1}$, Gonzalo Sáez-Calvo ${ }^{2}$, Natacha Olieric ${ }^{1}$, Francisco de Asís Balaguer ${ }^{2}$, \\ Isabel Barasoain ${ }^{2}$, Clemens Lamberth ${ }^{3}$, J. Fernando Díaz ${ }^{2, *}$ and Michel O. Steinmetz ${ }^{1, *}$ \\ 1 Laboratory of Biomolecular Research, Division of Biology and Chemistry, Paul Scherrer Institut, \\ CH-5232 Villigen, Switzerland; ashwani.sharma@psi.ch (A.S.); natacha.olieric@psi.ch (N.O.) \\ 2 Centro de Investigaciones Biológicas, Consejo Superior de Investigaciones Científicas, Ramiro de Maeztu 9, \\ 28040 Madrid, Spain; g.saez.calvo@gmail.com (G.S.-C.); \\ pacobal@cib.csic.es (F.d.A.B.); i.barasoain@cib.csic.es (I.B.) \\ 3 Chemical Research, Syngenta Crop Protection AG, Schaffhauserstrasse 101, CH-4332 Stein, Switzerland; \\ clemens.lamberth@syngenta.com \\ * Correspondence: fer@cib.csic.es (J.F.D.); michel.steinmetz@psi.ch (M.O.S.); \\ Tel.: +34-918-373-112 (J.F.D.); +41-56-310-4754 (M.O.S.)
}

Received: 26 April 2017; Accepted: 18 June 2017; Published: 22 June 2017

\begin{abstract}
Quinolin-6-yloxyacetamides (QAs) are a chemical class of tubulin polymerization inhibitors that were initially identified as fungicides. Here, we report that QAs are potent anti-proliferative agents against human cancer cells including ones that are drug-resistant. QAs act by disrupting the microtubule cytoskeleton and by causing severe mitotic defects. We further demonstrate that QAs inhibit tubulin polymerization in vitro. The high resolution crystal structure of the tubulin-QA complex revealed that QAs bind to the colchicine site on tubulin, which is targeted by microtubule-destabilizing agents such as colchicine and nocodazole. Together, our data establish QAs as colchicine-site ligands and explain the molecular mechanism of microtubule destabilization by this class of compounds. They further extend our structural knowledge on antitubulin agents and thus should aid in the development of new strategies for the rational design of ligands against multidrug-resistant cancer cells.
\end{abstract}

Keywords: microtubules; microtubule targeting agents; quinolin-6-yloxyacetamides; multidrug resistance

\section{Introduction}

Since their first description [1], 40 years of research on microtubule targeting agents (MTAs) has expanded our knowledge of biologically potent tubulin-binding compounds. Many studies led to the characterization of new microtubule targeting agent (i.e., microtubule-stabilizing and -destabilizing agents; referred to as MSAs and MDAs, respectively), some of which are routinely used in the clinic and a large number of which are currently under clinical development. In recent years, high resolution structural studies on tubulin-drug complexes have played a key role in understanding the mechanism of action of MTAs and has inspired the development of more efficient drugs [2,3]. MSAs targeting the taxane site of tubulin are, for example, able to change the conformation of the M-loop of $\beta$-tubulin. This conformational change is essential to strengthen the lateral contacts between protofilament in microtubules [4], and to revert changes induced by GTP (guanosine triphosphate) hydrolysis at the longitudinal tubulin-tubulin interface along protofilaments [5]. On the other hand, the laulimalide/peloruside class of ligands stabilizes microtubules both by partial structuration of the M-loop and by bridging two adjacent tubulin dimers across protofilaments in microtubules [6]. 
MDAs binding at the vinblastine- or maytansine site of tubulin act by interfering with longitudinal tubulin-tubulin interactions required for protofilament formation $[7,8]$, whereas those binding at the colchicine site act as "wedges" that prevent the required straightening of tubulin dimers during microtubule formation [9].

Despite the increased number of MTAs, two major problems are still encountered during their use as therapeutics: (1) the development of resistance against the available drugs and (2) the undesirable side effects. One strategy commonly used to overcome non-specific side effects is to exploit antibody-drug conjugates (ADCs) to specifically target cancer cells. This methodology can be further extended by attaching two different MTAs with different modes of action to one and the same antibody in order to decrease the chances of resistance development [10-12]. However, the identification and development of novel chemotypes seems the most promising strategy to overcome the problem of resistance development [13-15].

Quinolin-6-yloxyacetamides (QAs) were initially identified as fungicides that are highly active against several major phytopathogens [16]. They constitute a chemical class of ligands that acts by inhibiting tubulin polymerization [16]. However, their molecular mechanism of action remains unresolved. Here, we found that QAs have an anti-proliferative effect on human tumor cells. Importantly, QAs are highly effective in inhibiting the proliferation of multidrug-resistant cancer cells that overexpress P-glycoproteins. X-ray crystallography led to the identification of their binding site on tubulin and clarified the molecular mechanism underlying the microtubule destabilization activity of QAs.

\section{Results}

\subsection{Effect of Quinolin-6-Yloxyacetamides on Cells}

QAs act as fungicides by inhibiting tubulin polymerization [16]. In view of previous results, we wanted to evaluate the activity of QA derivatives on tumoural cells. To do so, we assessed the anti-proliferative activity of three different $\mathrm{QA}$ derivatives (denoted by $\mathrm{QA}_{1}, \mathrm{QA}_{2}$, and $\mathrm{QA}_{3}$; Figure 1) against ovarian and P-glycoprotein (PGP)-overexpressing human carcinoma cell lines (A2780 and A2780AD, respectively), lung carcinoma A549, and NIH mouse embryo $3 \mathrm{~T} 3$ cells using an MTT (3-(4,5-dimethylthiazol-2-yl)-2,5-diphenyltetrazolium bromide)-based assay. The $\mathrm{IC}_{50}$ values after a 48-h treatment are summarized in Table 1. We found that all three QA compounds tested show anti-proliferative effects on A2780 and A549 cells in the sub-micromolar range, with $\mathrm{QA}_{1}$ and $\mathrm{QA}_{2}$ being more potent than $\mathrm{QA}_{3}$. Importantly, their growth inhibitory effect remains essentially unchanged in multiple drug-resistant PGP overexpressing A2780AD cells, since their $\mathrm{IC}_{50}$ values in both $\mathrm{A} 2780$ and $\mathrm{A} 2780 \mathrm{AD}$ cells are not statistically different. In comparison to paclitaxel, which displays a resistance index of 916, in A2780AD cells the resistance index towards QAs is less than 3.

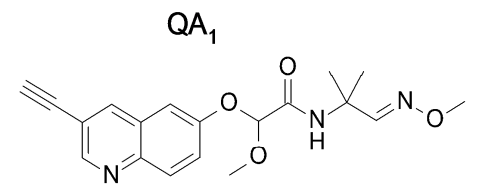

2-[(3-ethynyl-6-quinolyl)oxy]-2-met

hoxy- $N$-[2-methoxyimino-1,1-dimet hy-ethyl]acetamide

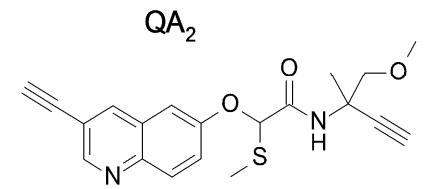

2-[(3-ethynyl-6-quinolyl)oxy]- $N$-[1-(methoxym

ethyl)-1-methyl-prop-2-ynyl]-2-methylsulfanyl -acetamide

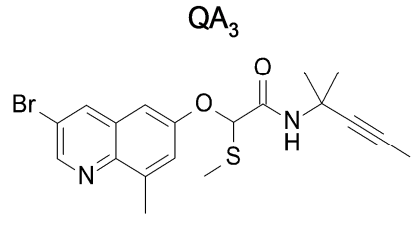

2-[(3-bromo-8-methyl-6-quinolyl)oxy]- $N$-(dime thylbut-2-ynyl]-2-methylsulfanyl-acetamide

Figure 1. Chemical structures of the quinolin-6-yloxyacetamides compounds used in this study. 
Table 1. Anti-proliferative effect of quinolin-6-yloxyacetamides in A2780, A2780AD, A549, and 3 T3 cells.

\begin{tabular}{cccccc}
\hline Compound & A549 & A2780 & A2780AD & R/S & 3T3 \\
\hline QA $_{1}$ & $60 \pm 2$ & $71 \pm 14$ & $141 \pm 42$ & 1.9 & $79 \pm 5$ \\
$\mathrm{QA}_{2}$ & $44.3 \pm 11$ & $104 \pm 8$ & $262 \pm 85$ & 2.5 & $125 \pm 9$ \\
$\mathrm{QA}_{3}$ & $707 \pm 23$ & $900 \pm 100$ & $800 \pm 80$ & 0.9 & $2400 \pm 600$ \\
Paclitaxel & $3.2 \pm 1$ & $1.2 \pm 0.1$ & $1100 \pm 300$ & 916 & $\mathrm{ND}$ \\
Colchicine & $55 \pm 4$ & $13.6 \pm 2$ & $663 \pm 23$ & 48 & $62.2 \pm 4$ \\
\hline
\end{tabular}

$\mathrm{IC}_{50}(\mathrm{nM}$, mean \pm standard error) values of the ligands determined in lung carcinoma $\mathrm{A} 549$, in ovarian carcinoma A2780 and A2780AD, and mouse embryo NIH 3T3 (3T3) cell lines. The resistance index, R/S, is obtained by dividing the $\mathrm{IC}_{50}$ of the resistant A2780AD cell line by that of the parental A2780 cell line. ND, not determined. Values represent the mean \pm standard error of three independent experiments.

Given the fact that the compounds were found to have growth inhibitory effects, we continued to investigate their actual cellular mechanism of action in human cells. Since MTAs usually induce G2/M cell cycle arrest, the effect of QAs on the cell cycle was studied for each compound with A549 lung carcinoma cells for $20 \mathrm{~h}$ by flow cytometry. Figure 2 shows the DNA histograms in the presence of ligands and controls. The results indicate that all three QAs block cells in the G2/M phase of the cell cycle, indicating an antimitotic mode of action. The Supplementary Table S1 summarizes the percentage of cells in each phase of the cell cycle and at the indicated ligand concentrations.

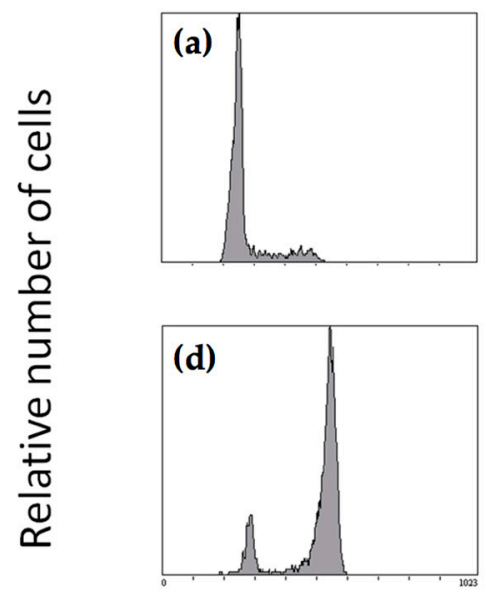

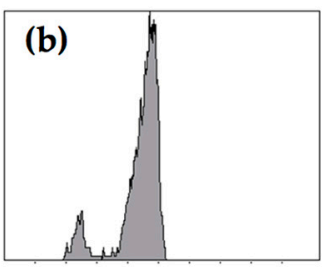
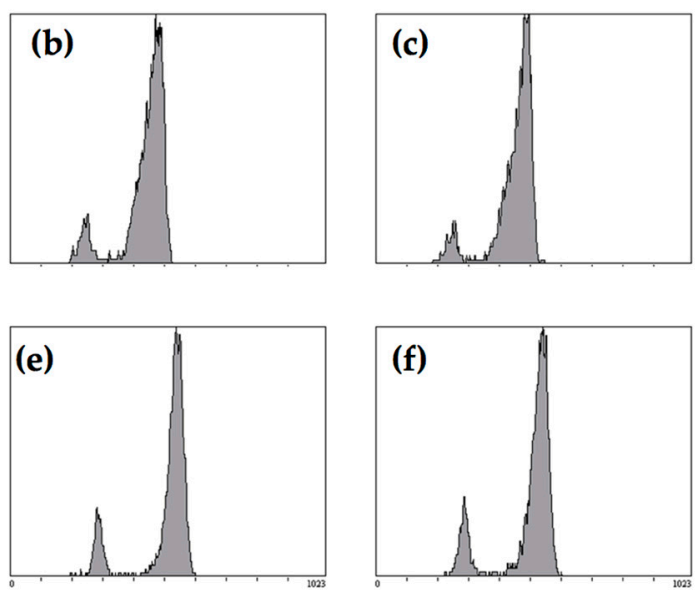

\section{Relative DNA content (PI fluorescence)}

Figure 2. Cell cycle histograms. A549 lung carcinoma cells were incubated for $20 \mathrm{~h}$ with either (a) DMSO (Dimethylsulfoxyde); (b) $250 \mathrm{nMQA}_{1}$; (c) $250 \mathrm{nMQA}$; (d) $10 \mu \mathrm{MQA}_{3}$; (e) $100 \mathrm{nM}$ Colchicine; or (f) $50 \mathrm{nM}$ Pironetin. The histograms shown correspond to the lowest ligand concentration that induces maximal cell cycle arrest in the G2/M phase, and are generated by counting 5000 cells by flow cytometry.

\subsection{Effect on Cellular Microtubules}

To probe the effect of QAs on the microtubule cytoskeleton and on the mitotic spindle, we incubated A549 cells with serial concentrations of compounds for $24 \mathrm{~h}$ followed by immunofluorescence analysis. Compared to control cells, the three QA compounds tested exerted a depolymerizing effect that is highlighted by the fragmented microtubule cytoskeleton seen in all treated cells (Figure 3). Although all the compounds of the QA series were effective in disrupting cellular microtubules in the low micromolar range, compounds $\mathrm{QA}_{1}$ and $\mathrm{QA}_{2}$ were the most potent: $100 \mathrm{nM}$ of either of them induced mitotic aberrations (Figure $3 \mathrm{~b}, \mathrm{e}$ ). Complete depolymerization of the interphasic microtubule cytoskeleton was achieved in both cases at $0.5-1 \mu \mathrm{M}$ of compound (Figure $3 \mathrm{~d}, \mathrm{f})$. In the case of $\mathrm{QA}_{3}$, the 
microtubules were almost not observable anymore in the presence of $3 \mu \mathrm{M}$ of the compound (Figure $3 \mathrm{~h}$ ). Furthermore, $10 \mathrm{nM}$ of vinblastine used as a control induced aberrant forms of bipolar spindles (type II spindles) with lagging chromosomes (Figure 3 , inset i), a phenotype that was also seen with $\mathrm{QA}_{1}$ and $\mathrm{QA}_{2}$ at the lowest concentrations tested (100 nM, not shown). Type III and IV spindles were seen with 250 and $1 \mu \mathrm{M}$ of either $\mathrm{QA}_{1}$ and $\mathrm{QA}_{2}$, and with either $3 \mu \mathrm{M}$ of $\mathrm{QA}_{3}$ (Figure 3, insets c,d,f,h) or $50 \mathrm{nM}$ of vinblastine. Vinblastine effects on microtubules have been reported previously [17], chromosomes were arranged in a "ball" enclosing one or more star-shaped aggregates of tubulin/microtubules; in some cases, no microtubules could be seen, and with $50 \mathrm{nM}$ vinblastine a complete depolymerization of the microtubule cytoskeleton was observed (Figure 3j).
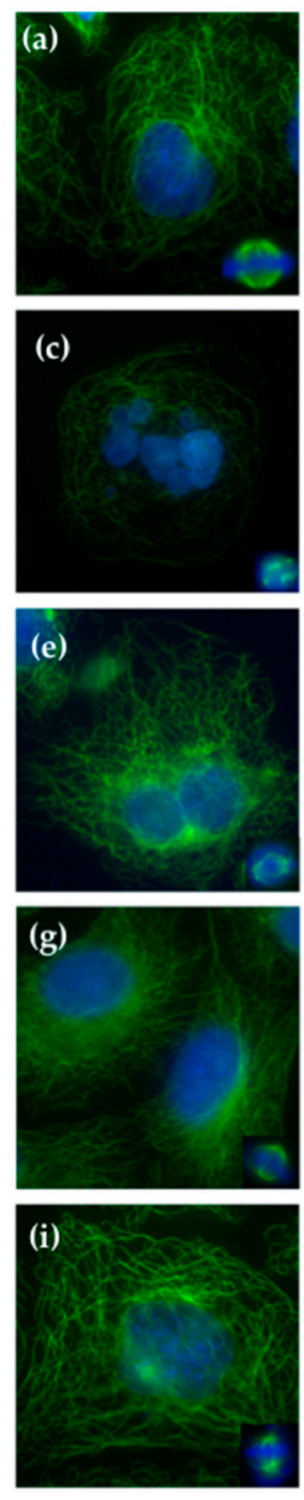
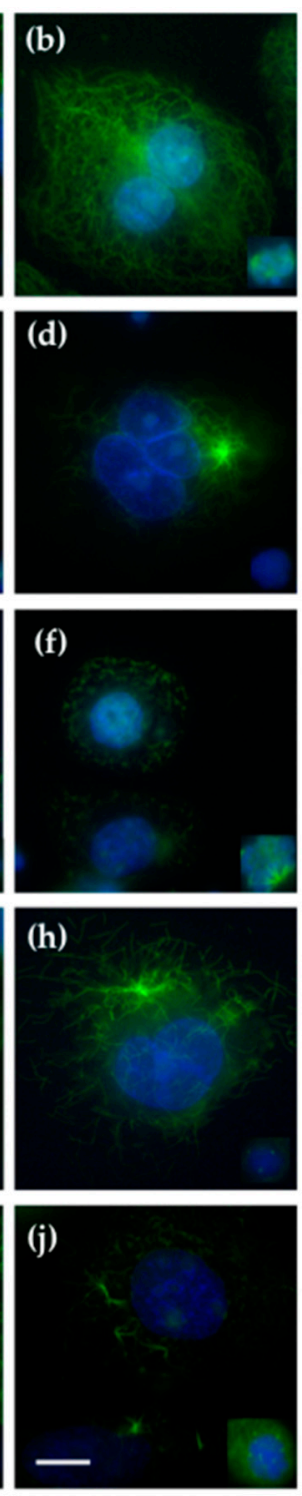

Figure 3. Effect of quinolin-6-yloxyacetamides on the microtubule cytoskeleton network and mitotic spindles. A549 cells were treated either with (a) DMSO; (b) $100 \mathrm{nM} \mathrm{QA}_{1}$; (c) $250 \mathrm{nM} \mathrm{QA}$; or (d) 0.5-1 $\mu \mathrm{M} \mathrm{QA}_{1}$; (e) $100 \mathrm{nM} \mathrm{QA}_{2}$; (f) 0.5-1 $\mu \mathrm{M} \mathrm{QA}_{2}$; (g) $1 \mu \mathrm{M} \mathrm{QA}_{3}$; (h) 3-5 $\mu \mathrm{M} \mathrm{QA} 3$; (i) $10 \mathrm{nM}$ vinblastine; or (j) $50 \mathrm{nM}$ vinblastine. Microtubules are stained with $\alpha$-tubulin antibodies (green); DNA was stained with Hoechst 33342 (blue). The insets are mitotic spindles from the same preparations. Scale bar, $10 \mu \mathrm{m}$. All panels and insets have the same magnification. 


\subsection{Effect of Quinolin-6-Yloxyacetamides on Microtubule Formation In Vitro}

To gain further insight into the molecular mechanism of action of QAs, we tested their effect on the assembly of microtubules by using a standard tubulin polymerization assay (Figure 4). Briefly, twenty $\mu \mathrm{M}$ of tubulin was incubated in glycerol-assembly buffer (GAB) for $70 \mathrm{~min}$ at $37^{\circ} \mathrm{C}$ in the presence of different amounts $(2-25 \mu \mathrm{M})$ of compounds. The degree of tubulin polymerization was then evaluated by monitoring the absorbance at $350 \mathrm{~nm}$. We found that all QAs were strong inhibitors of tubulin polymerization, with almost complete inhibition of tubulin polymerization at $5 \mu \mathrm{M}$ concentration of compounds. The polymerization inhibition observed for each compound is in agreement with their anti-proliferative activity.
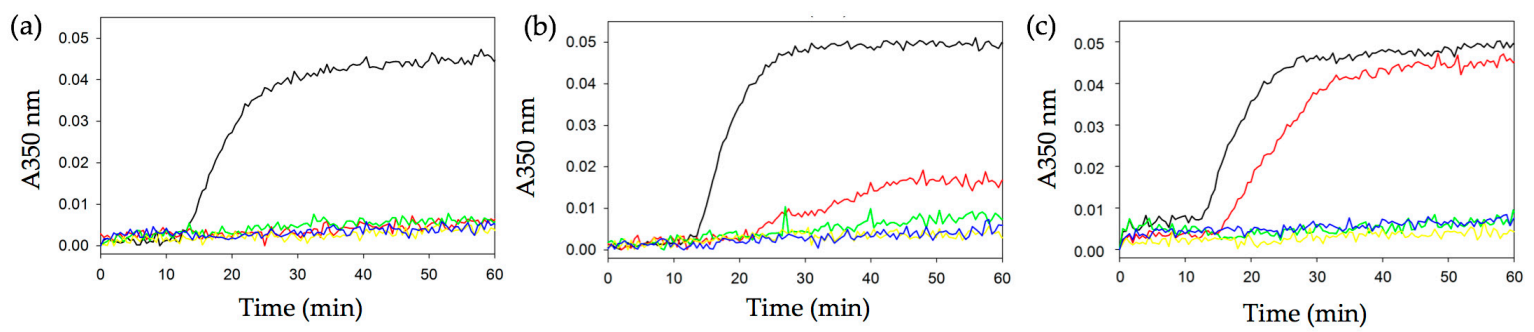

Figure 4. In vitro tubulin polymerization. Turbidity assays for the assembly of $20 \mu \mathrm{M}$ tubulin at $37^{\circ} \mathrm{C}$ in the presence of $\mathrm{QA}_{1}(\mathbf{a}), \mathrm{QA}_{2}(\mathbf{b})$, and $\mathrm{QA}_{3}(\mathbf{c})$ followed at $350 \mathrm{~nm}$. Black line, DMSO vehicle; red line, $2 \mu \mathrm{M} \mathrm{QA}$; green line, $5 \mu \mathrm{M}$ QA; yellow line, $10 \mu \mathrm{M} \mathrm{QA}$; blue line, $25 \mu \mathrm{M} \mathrm{QA}$.

\subsection{Crystal Structure of the Tubulin- $Q A_{1}$ Complex}

To understand the binding mode and mechanism of action of QAs on tubulin and microtubules, we solved the crystal structure of $\alpha \beta$-tubulin in complex with the most potent compound, $\mathrm{QA}_{1}$, by using the well-established $\mathrm{T}_{2} \mathrm{R}$-TTL crystallization system [4]. The $\mathrm{T}_{2} \mathrm{R}$-TTL- $\mathrm{QA}_{1}$ complex structure was determined at $2.4 \AA$ resolution (Supplementary Table S2). Unambiguous difference electron density for $\mathrm{QA}_{1}$ was observed on both tubulin subunits in the $\mathrm{T}_{2} \mathrm{R}-\mathrm{TTL}-\mathrm{QA} \mathrm{A}_{1}$ complex, which led us to model the drug molecule confidently (Supplementary Figure S1a).

$\mathrm{QA}_{1}$ binds at the colchicine site on tubulin [18], which is located at the interface between the $\alpha$ and $\beta$-tubulin subunits. It is formed by strands $\beta S 1, \beta S 4, \beta S 6, \beta S 7, \beta S 8, \beta S 9$, and $\beta S 10$, loop $\beta T 7$, and helices $\beta \mathrm{H} 7$ and $\beta \mathrm{H} 8$ of $\beta$-tubulin, as well as the loop $\alpha \mathrm{T} 5$ of $\alpha$-tubulin (Figure 5). Similar to nocodazole [19], although the $\alpha \mathrm{T} 5$ loop adopts a different conformation upon $\mathrm{QA}_{1}$ binding compared to the apo tubulin structure (Figure 6a), we did not observe any direct interactions between $\mathrm{QA}_{1}$ and $\alpha \mathrm{T} 5$ loop residues. The overall structure of tubulin in the $\mathrm{T}_{2} \mathrm{R}-\mathrm{TTL}-\mathrm{QA}_{1}$ complex could be readily superimposed with the one obtained in the absence of the ligand (root-mean-square deviation, rmsd, of $0.43 \AA$ over $1904 \mathrm{C} \alpha$ atoms), suggesting that binding of $\mathrm{QA}_{1}$ does not affect the global conformation of the tubulin dimer in the curved state.

$\mathrm{QA}_{1}$ binding is mostly established by hydrophobic contacts and a few hydrogen bond interactions with residue side chains of $\beta$-tubulin. The ethenyl group at the $3^{\prime}$ position of the quinoline ring of $\mathrm{QA}_{1}$ is accommodated in a hydrophobic pocket in $\beta$-tubulin delineated by residues $\beta$ L252, $\beta$ F169, $\beta \mathrm{L} 242, \beta$ T239, $\beta$ Y52, $\beta$ Q136, and $\beta$ I4 (Figure $5 c$ ). The nitrogen atom of the quinolone group is involved in hydrogen bond interaction with the side chains of $\beta E 200$ and $\beta Y 202$. The quinolone ring is accommodated in a hydrophobic cavity formed by the side chains of residues $\beta$ L242, $\beta$ L252, $\beta$ L255 $\beta$ F268, $\beta$ I378, and $\beta$ V238 (Figure $5 c, d$ ). The methoxy group substituent in the acetic acid moiety of $\mathrm{QA}_{1}$ makes hydrophobic contacts with the side chains of $\beta \mathrm{I} 318$ and $\beta \mathrm{I} 378$ (Figure $5 \mathrm{~d}$ ), whereas the methoxyimino moiety resides in a pocket lined by residues $\beta$ A354, $\beta \mathrm{L} 248$, and $\beta$ K352. Most of the $\beta$-tubulin residues involved in the interaction with $\mathrm{QA}_{1}$ are conserved between mammalian and fungal tubulins, explaining the growth inhibitory effect of QAs against both fungal and mammalian cells (Supplementary Figure S1b). 
(a)

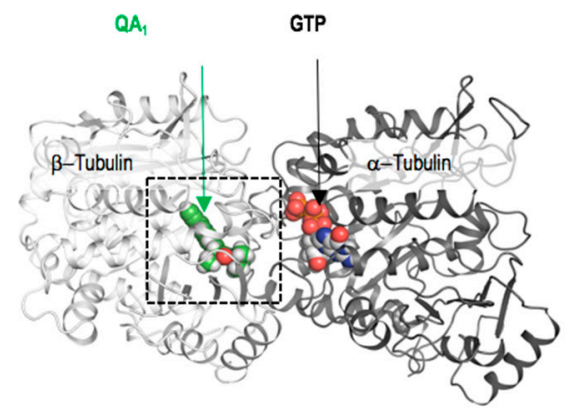

(c)

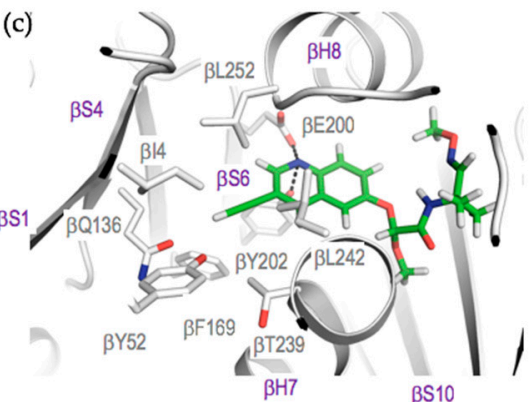

(b)

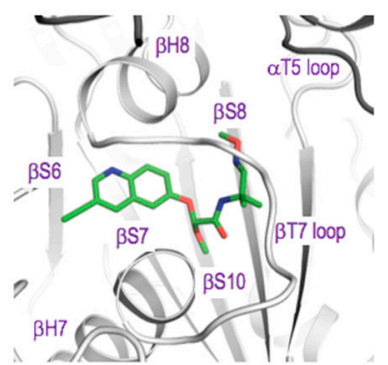

(d)

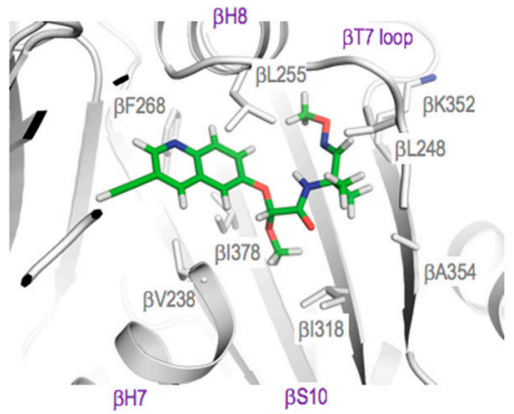

Figure 5. $\mathrm{QA}_{1}$ binds at the colchicine site of tubulin. (a) Overall view of the tubulin-QA $\mathrm{A}_{1}$ complex. $\mathrm{QA}_{1}$ is displayed as green spheres; (b) A close up view of the region highlighted with a dashed rectangle in (a) and showing the $\mathrm{QA}_{1}$ binding site. $\mathrm{QA}_{1}$ is displayed as green sticks. Major secondary structure elements are labelled; $(\mathbf{c}, \mathbf{d})$ Interacting residues of $\beta$-tubulin with $\mathrm{QA}_{1}$. Oxygen and nitrogen atoms are displayed in red and blue, respectively.

A comparison of the $\beta$-tubulin subunit between the apo- $\mathrm{T}_{2} \mathrm{R}-\mathrm{TTL}$ (Protein Data Bank (PDB) ID $4 \mathrm{I} 55)$ and $\mathrm{T}_{2}$ R-TTL-QA 1 shows that the $\beta$ T7 loop residues $\beta$ L248 and $\beta$ N249 of $\beta$-tubulin occupies the $\mathrm{QA}_{1}$ site in the apo structure. Therefore, to accommodate $\mathrm{QA}_{1}$ in its binding site, the $\beta \mathrm{T} 7$ loop has to flip outwards and the $\alpha \mathrm{T} 5$ loop of $\alpha$-tubulin has to change its conformation (Figure 6a). Similar conformational changes have been observed upon binding of other colchicine site ligands to tubulin $[3,9,18]$.

Since QAs form a chemical class of colchicine site binders that are structurally unrelated to colchicine, we superimposed the $\mathrm{T}_{2} \mathrm{R}$-TTL-colchicine structure onto the $\mathrm{T}_{2} \mathrm{R}$-TTL-QA 1 structure. The overall conformation of tubulin remains unchanged between the two structures (rmsd of 0.27 over 1973 CA atoms). Despite sharing the same binding pocket, only the methoxyimino group of QA $_{1}$ overlaps with the colchicine molecule, whereas the quinoline ring of $\mathrm{QA}_{1}$ explores regions deep in the $\beta$-tubulin subunit remote from colchicine. Interestingly, the quinoline ring of $\mathrm{QA}_{1}$ overlaps with nocodazole, which is another colchicine site binder (Figure 6b). QAs are thus a new chemical class of colchicine site, tubulin polymerization inhibitors that bind to an overlapping site in tubulin that is located between the ones of colchicine and nocodazole.

The two tubulin dimers in the $\mathrm{T}_{2} \mathrm{R}$-TTL structure assume the "curved" conformation characteristic of free tubulin, in contrast with the "straight" tubulin structure that is found in microtubules. To assess whether the binding of $\mathrm{QA}_{1}$ is compatible with the straight tubulin conformation present in microtubules, we compared the structures of tubulin in the curved and straight conformational states. We found that in straight tubulin, the $\mathrm{QA}_{1}$ binding site is occluded by the $\beta \mathrm{T} 7$ loop of $\beta$-tubulin, resulting in severe clashes between the $\beta$ T7 loop residues with the $\mathrm{QA}_{1}$ molecule in the modelled tubulin-QA 1 structure (Figure 6c). Therefore, QAs cannot bind to preformed microtubules. QAs thus act as microtubule destabilizers by binding to curved tubulin in solution and preventing the curved-to-straight structural transition required for microtubule formation [18]. Together, these data establish QAs as microtubule destabilizers of the colchicine site. 
(a)

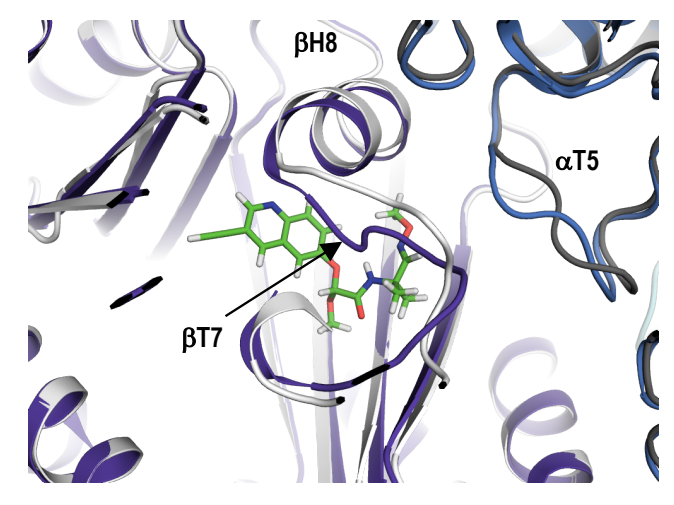

(b)

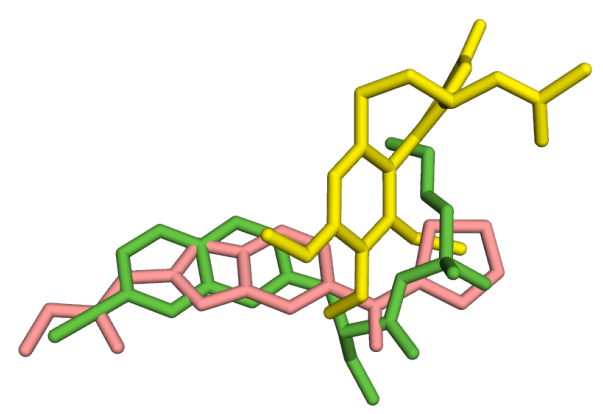

(c)

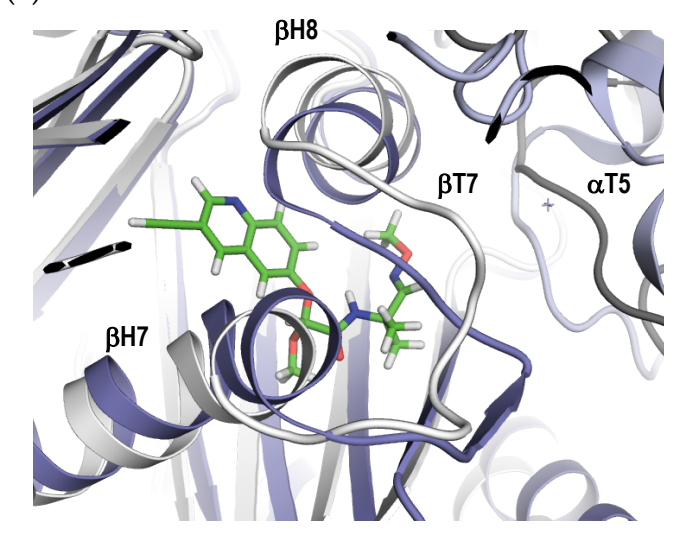

Figure 6. Mechanism of $\mathrm{QA}_{1}$-mediated microtubule destabilization. (a) Superimposition of tubulin in its $\mathrm{QA}_{1}$ bound (white ribbons, $\beta$-tubulin; grey ribbons, $\alpha$-tubulin) and unliganded (purple ribbons, $\beta$-tubulin; blue ribbons, $\alpha$-tubulin). The $\beta$-tubulin subunits were used for the superimposition. $\mathrm{QA}_{1}$ is displayed as green sticks; (b) Superimposition of $\mathrm{QA}_{1}$ (green sticks) with colchicine (yellow sticks, PDB ID 4O2B) and nocodazole (pink sticks, PDB ID 5CA1); (c) Superimposition of $\mathrm{QA}_{1}$ bound "curved" tubulin (white) with "straight" tubulin in microtubules (purple). $\mathrm{QA}_{1}$ is displayed as green sticks. Oxygen and nitrogen atoms are displayed in red and blue, respectively.

\section{Discussion}

MTAs include a wide variety of small molecules with diverse chemical structures. They interfere with microtubule dynamics, which is an essential process for many cell functions including cell division, angiogenesis, cell migration, and intracellular transport. Because of their anti-proliferative properties, MTAs remain one of the most active areas of research for cancer treatment. Several MTAs are used in cancer chemotherapy and many others are in clinical trials. However, the development of resistance against the available drugs is a major challenge that necessitates the search for and development of MTAs with novel chemical structures and mechanisms of action.

Six distinct ligand binding sites (taxane [20], colchicine [18], vinca [21], laulimalide/peloruside [6], pironetin [22,23], and maytansine [7]) were characterized on tubulin to high resolution using X-ray crystallography. It is well established that ligands belonging to different chemical classes can bind to a common binding site on tubulin and perturb microtubule functions using similar mechanisms of action [19]. Therefore, the search for tubulin inhibitors with novel chemical structures targeting the known drug binding sites on tubulin offers an attractive alternative strategy to overcome multiple drug resistance. However, the rational development of tubulin inhibitors requires the availability of atomic resolution structural information on tubulin-ligand complexes. In this work, we show that QAs 
constitute a favorable chemical class of MTAs that are highly toxic to multidrug-resistant human cancer cells overexpressing P-glycoproteins. We further show that QAs target cellular microtubules, inducing systemic microtubule depolymerization and gross mitotic defects. By solving the high resolution crystal structure of tubulin in complex with $\mathrm{QA}_{1}$, we could unambiguously determine that QAs bind to the colchicine site of tubulin. $\mathrm{QA}_{1}$ binding prevents the conformational changes in the $\beta \mathrm{T} 7$ loop of $\beta$-tubulin accompanying the curved-to-straight tubulin conformational transition required for microtubule formation. Based on our data, we propose that the primary mechanism of action of QAs is to bind to the curved conformational state of tubulin, either when free in solution or when incorporated at the ends of growing microtubules, to lock the protein in a polymerization incompetent state; a similar mechanism of action was postulated for other colchicine site antitubulin ligands [2,24].

Although clinical trials with several colchicine-site ligands are ongoing, none have yet been approved and no colchicine-site ligand is currently in active clinical application, highlighting the need to develop colchicine-site agents. Many structurally diverse ligands are known to target the colchicine site of tubulin and to differentially explore its sub-pockets $[3,19]$. In this context, QAs with their favorable chemical scaffolds and activity profiles against multi drug resistant (MDR) cancer cells represent attractive colchicine-site ligand candidates. Our structural and biochemical work on QAs presented here may thus offer a favorable basis for the rational design of novel and potent QA derivatives against different types of tumors.

\section{Materials and Methods}

\subsection{Proteins and Ligands}

Purified calf-brain tubulin and chemicals were prepared as described previously [25]. Compounds $\mathrm{QA}_{1-3}$ (Figure 1) were synthesized as described [26-28]. They were dissolved in D6-DMSO at a concentration of $20 \mathrm{mM}$ and stored at $-80^{\circ} \mathrm{C}$. The compounds were analyzed using an Agilent 1100 chromatograph connected to a reverse phase column Zorbax Eclipse XDB-C18 (mobile phase 70\% methanol in water for $20 \mathrm{~min}$ ) coupled to an Agilent 6120 mass spectrometer. All the compounds were found to be more than $95 \%$ pure. MS-HPLC analyses revealed the expected molecular weights for all three compounds. Their solubility in water was determined by centrifuging at $110,000 \times g$. Then, $50 \mu \mathrm{M}$ samples were stored in polypropylene or glass tubes in $10 \mathrm{mM}$ sodium phosphate, $\mathrm{pH}$ 6.5, 3.4 M glycerol, $1 \mathrm{mM}$ EGTA (ethylene-bis(oxyethylenenitrilo)tetraacetic acid), $6 \mathrm{mM} \mathrm{MgCl} 2,0.1 \mathrm{mM}$ GTP. The concentration of each compound in solution was determined spectrophotometrically before and after centrifugation. All the compounds were found to be soluble at a concentration of $50 \mu \mathrm{M}$.

\subsection{Tubulin Polymerization Assay}

Polymerization of tubulin in vitro was performed with $100 \mu \mathrm{L}$ samples and monitored by absorbance at $350 \mathrm{~nm}$ (Filter A00019x) in 96-well plates (Falcon, transparent, flat bottom) with an Appliskan plate reader (Thermo Fisher Scientific, Waltham, MA, USA). Subsequently, twenty $\mu \mathrm{M}$ of tubulin in GAB buffer (10 mM sodium phosphate, $\mathrm{pH}$ 6.7, 30\% glycerol, $1 \mathrm{mM}$ EGTA, $6 \mathrm{mM} \mathrm{MgCl}_{2}$, $1 \mathrm{mM}$ GTP) was supplemented with increasing amounts of the compounds up to $25 \mu \mathrm{M}$, or with DMSO as a vehicle control. Reactions were monitored for $70 \mathrm{~min}$ at $37^{\circ} \mathrm{C}$. Data were exported using the Thermo Scientific SkanIt software of Appliskan (version 2.3, Thermo Scientific, Waltham, MA, USA), and Excel software was used to generate plots. For convenience, data were normalized to the minimum absorbance value of the initial stable plateau.

\subsection{Cell Culture and Cell Biology Assays}

Human A549 non-small lung carcinoma cells and human ovarian carcinomas A2780 and A2780AD (MDR overexpressing P-glycoprotein) were cultured as previously described [29]. NIH 3T3 mouse embryo cells were cultured in DMEM (Dulbecco's modified eagle medium) supplemented with $10 \%$ FCS (fetal calf serum), penicillin (100 units $/ \mathrm{mL}$ ) and streptomycin $(100 \mu \mathrm{g} / \mathrm{mL})$. Indirect 
immunofluorescence, cell cycle analysis, and cytotoxicity assays were performed as described before [30]. The statistical significance of differences in $\mathrm{IC}_{50}$ values was evaluated using the $t$-test option implemented in the Sigma Plot 13 software package (version 13, Systat Software, Inc., San Jose, CA, USA).

\subsection{Complex Reconstitution, Crystallization and Soaking of $T_{2} R$-TTL (Tubulin-RB3-Tubulin Tyrosine Ligase Complex) Crystals with $Q A_{1}$}

Crystals of $T_{2} R$-TTL were generated as described previously [4,31]. Suitable $T_{2} R$-TTL crystals were incubated for $3 \mathrm{~h}$ with reservoir solution supplemented with $5 \mathrm{mM}_{\text {of }} \mathrm{QA}_{1}$ and $18 \%$ glycerol as cryoprotectant. Crystals were flash-cooled in liquid nitrogen.

\subsection{Data Collection and Structure Solution}

A single $\mathrm{T}_{2} \mathrm{R}$-TTL-QA $\mathrm{A}_{1}$ crystal was used for the collection of native $\mathrm{X}$-ray diffraction data at $100 \mathrm{~K}$ at the X06DA beamline at the Swiss Light Source (Paul Scherrer Institut, Villigen, Switzerland). Data were processed using the XDS software package [32]. The $\mathrm{T}_{2} \mathrm{R}-\mathrm{TTL}-\mathrm{QA} \mathrm{A}_{1}$ complex crystallized in space group $\mathrm{P} 2{ }_{1} 2_{1} 2_{1}$ with a single molecule in the asymmetric unit. Structure solution and refinement was performed using the PHENIX software package [33] as described previously [4,31]. Briefly, phases from the $\mathrm{T}_{2} \mathrm{R}$-TTL complex (PDB ID 4I4T) in the absence of ligands and solvent were used for a structure solution by a few cycles of rigid-body refinement in PHENIX. The model was further refined using multiple cycles of simulated annealing and restraint refinement. The resulting model was improved through the iterative model rebuilding in Coot [34] and refinement in PHENIX. The quality of the structure was assessed with MolProbity [35].

Data collection and refinement statistics are given in Supplementary Table S2. Figures were prepared using PyMOL (The PyMOL Molecular Graphics System, Version 1.4.1. Schrödinger, LLC, (Cambridge, MA, USA)).

Supplementary Materials: Supplementary materials can be found at www.mdpi.com/1422-0067/18/7/1336/s1. Coordinates and structure factors for T2R-TTL-QA ${ }_{1}$ have been deposited in the PDB with the accession code 5O7A.

Acknowledgments: We thank Michel.M. Gottesman for the NIH 3T3 embryo cells (NIH, Bethesda USA) and Ganadería Fernando Díaz for calf brains for tubulin purification. This work was supported by grants from Spanish Ministerio de Economía y Competitividad (BFU2016-75319-R (AEI/FEDER, UE) to J. Fernando Díaz) and from the Swiss National Science Foundation (31003A_166608 to Michel O. Steinmetz). The authors acknowledge networking contribution by the COST (European Cooperation in Science and Technology) Action CM1407 "Challenging organic syntheses inspired by nature-from natural products chemistry to drug discovery". X-ray data were collected at beamline X06DA of the Swiss Light Source (Paul Scherrer Institut, Villigen, Switzerland). Ashwani Sharma was supported by an EMBO (European Molecular Biology Organization) Long Term Fellowship, J. Fernando Díaz is member of the CIB Intramural Program "Molecular Machines for Better Life" (MACBET).

Author Contributions: Ashwani Sharma, Gonzalo Sáez-Calvo, Natacha Olieric, and Francisco de Asís Balaguer conducted and analyzed the biochemical, cell biology, and X-ray diffraction experiments. Isabel Barasoain designed and analyzed the cell biology experiments. Michel O. Steinmetz designed the X-ray diffraction experiments and analyzed the structure. Clemens Lamberth prepared the compounds. J. Fernando Díaz designed and analyzed the biochemical experiments. Ashwani Sharma and Natacha Olieric wrote the manuscript with the input from all authors.

Conflicts of Interest: The authors declare no conflict of interest.
Abbreviations
QAs Quinolin-6-yloxyacetamides
MT Microtubules
MSA Microtubule stabilizing agent
MDA Microtubule destabilizing agent 


\section{References}

1. Schiff, P.B.; Fant, J.; Horwitz, S.B. Promotion of microtubule assembly in vitro by taxol. Nature 1979, 277, 665-667. [CrossRef] [PubMed]

2. Akhmanova, A.; Steinmetz, M.O. Control of microtubule organization and dynamics: Two ends in the limelight. Nat. Rev. Mol. Cell Biol. 2015, 16, 711-726. [CrossRef] [PubMed]

3. Dorleans, A.; Gigant, B.; Ravelli, R.B.G.; Mailliet, P.; Mikol, V.; Knossow, M. Variations in the colchicine-binding domain provide insight into the structural switch of tubulin. Proc. Natl. Acad. Sci. USA 2009, 106, 13775-13779. [CrossRef] [PubMed]

4. Prota, A.E.; Bargsten, K.; Zurwerra, D.; Field, J.J.; Diaz, J.F.; Altmann, K.-H.; Steinmetz, M.O. Molecular mechanism of action of microtubule-stabilizing anticancer agents. Science 2013, 339, 587-590. [CrossRef] [PubMed]

5. Alushin, G.M.; Lander, G.C.; Kellogg, E.H.; Zhang, R.; Baker, D.; Nogales, E. High-resolution microtubule structures reveal the structural transitions in $\alpha \beta$-tubulin upon GTP hydrolysis. Cell 2014, 157, 1117-1129. [CrossRef] [PubMed]

6. Prota, A.E.; Bargsten, K.; Northcote, P.T.; Marsh, M.; Altmann, K.-H.; Miller, J.H.; Diaz, J.F.; Steinmetz, M.O. Structural basis of microtubule stabilization by laulimalide and peloruside A. Angew. Chem. Int. Ed. Engl. 2014, 53, 1621-1625. [CrossRef] [PubMed]

7. Prota, A.E.; Bargsten, K.; Diaz, J.F.; Marsh, M.; Cuevas, C.; Liniger, M.; Neuhaus, C.; Andreu, J.M.; Altmann, K.-H.; Steinmetz, M.O. A new tubulin-binding site and pharmacophore for microtubule-destabilizing anticancer drugs. Proc. Natl. Acad. Sci. USA 2014, 111, 13817-13821. [CrossRef] [PubMed]

8. Doodhi, H.; Prota, A.E.; Rodriguez-Garcia, R.; Xiao, H.; Custar, D.W.; Bargsten, K.; Katrukha, E.A.; Hilbert, M.; Hua, S.; Jiang, K.; et al. Termination of protofilament elongation by eribulin induces lattice defects that promote microtubule catastrophes. Curr. Biol. 2016, 26, 1713-1721. [CrossRef] [PubMed]

9. Prota, A.E.; Danel, F.; Bachmann, F.; Bargsten, K.; Buey, R.M.; Pohlmann, J.; Reinelt, S.; Lane, H.; Steinmetz, M.O. The novel microtubule-destabilizing drug BAL27862 binds to the colchicine site of tubulin with distinct effects on microtubule organization. J. Mol. Biol. 2014, 426, 1848-1860. [CrossRef] [PubMed]

10. Hughes, B. Antibody-drug conjugates for cancer: Poised to deliver? Nat. Publ. Group 2010, 9, 665-667. [CrossRef] [PubMed]

11. Bouchard, H.; Viskov, C.; Garcia-Echeverria, C. Antibody-drug conjugates-a new wave of cancer drugs. Bioorg. Med. Chem. Lett. 2014, 24, 5357-5363. [CrossRef] [PubMed]

12. Lambert, J.M. Antibody-drug conjugates: Targeted delivery and future prospects. Ther. Deliv. 2016, 7, 279-282. [CrossRef] [PubMed]

13. Kizaki, M.; Hashimoto, Y. New tubulin polymerization inhibitor derived from thalidomide: Implications for anti-myeloma therapy. Curr. Med. Chem. 2008, 15, 754-765. [CrossRef] [PubMed]

14. Rozic, G.; Paukov, L.; Jakubikova, J.; Ben-Shushan, D.; Duek, A.; Leiba, A.; Avigdor, A.; Nagler, A.; Leiba, M. The novel compound STK405759 is a microtubule-targeting agent with potent and selective cytotoxicity against multiple myeloma in vitro and in vivo. Oncotarget 2016, 7, 62572-62584. [CrossRef] [PubMed]

15. Fryknas, M.; Gullbo, J.; Wang, X.; Rickardson, L.; Jarvius, M.; Wickstrom, M.; Hassan, S.; Andersson, C.; Gustafsson, M.; Westman, G.; et al. Screening for phenotype selective activity in multidrug resistant cells identifies a novel tubulin active agent insensitive to common forms of cancer drug resistance. BMC Cancer 2013, 13, 374. [CrossRef] [PubMed]

16. Lamberth, C.; Kessabi, F.M.; Beaudegnies, R.; Quaranta, L.; Trah, S.; Berthon, G.; Cederbaum, F.; Knauf-Beiter, G.; Grasso, V.; Bieri, S.; et al. Synthesis and fungicidal activity of quinolin-6-yloxyacetamides, a novel class of tubulin polymerization inhibitors. Bioorg. Med. Chem. 2014, 22, 3922-3930. [CrossRef] [PubMed]

17. Jordan, M.A.; Thrower, D.; Wilson, L. Effects of vinblastine, podophyllotoxin and nocodazole on mitotic spindles. Implications for the role of microtubule dynamics in mitosis. J. Cell Sci. 1992, 102, 401-416. [PubMed]

18. Ravelli, R.B.G.; Gigant, B.; Curmi, P.A.; Jourdain, I.; Lachkar, S.; Sobel, A.; Knossow, M. Insight into tubulin regulation from a complex with colchicine and a stathmin-like domain. Nature 2004, 428, 198-202. [CrossRef] [PubMed] 
19. Wang, Y.; Zhang, H.; Gigant, B.; Yu, Y.; Wu, Y.; Chen, X.; Lai, Q.; Yang, Z.; Chen, Q.; Yang, J. Structures of a diverse set of colchicine binding site inhibitors in complex with tubulin provide a rationale for drug discovery. FEBS J. 2016, 283, 102-111. [CrossRef] [PubMed]

20. Nogales, E.; Wolf, S.G.; Downing, K.H. Structure of the $\alpha \beta$ tubulin dimer by electron crystallography. Nature 1998, 391, 199-203. [CrossRef] [PubMed]

21. Gigant, B.; Wang, C.; Ravelli, R.B.G.; Roussi, F.; Steinmetz, M.O.; Curmi, P.A.; Sobel, A.; Knossow, M. Structural basis for the regulation of tubulin by vinblastine. Nature 2005, 435, 519-522. [CrossRef] [PubMed]

22. Prota, A.E.; Setter, J.; Waight, A.B.; Bargsten, K.; Murga, J.; Diaz, J.F.; Steinmetz, M.O. Pironetin binds covalently to $\alpha$ Cys 316 and perturbs a major loop and helix of $\alpha$-tubulin to inhibit microtubule formation. J. Mol. Biol. 2016, 428, 2981-2988. [CrossRef] [PubMed]

23. Yang, J.; Wang, Y.; Wang, T.; Jiang, J.; Botting, C.H.; Liu, H.; Chen, Q.; Yang, J.; Naismith, J.H.; Zhu, X.; Chen, L. Pironetin reacts covalently with cysteine-316 of $\alpha$-tubulin to destabilize microtubule. Nat. Commun. 2016, 7, 12103. [CrossRef] [PubMed]

24. Skoufias, D.A.; Wilson, L. Mechanism of inhibition of microtubule polymerization by colchicine: Inhibitory potencies of unliganded colchicine and tubulin-colchicine complexes. Biochemistry 1992, 31, 738-746. [CrossRef] [PubMed]

25. Andreu, J.M. Large scale purification of brain tubulin with the modified Weisenberg procedure. Methods Mol. Med. 2007, 137, 17-28. [PubMed]

26. Murphy Kessabi, F.; Brunner, H.-G.; Beaudegnies, R.; Quaranta, L.; Cederbaum, F. Novel Fungicides. WO 2009/030467, 12 March 2009.

27. Beaudegnies, R.; Murphy Kessabi, F.; Quaranta, L.; Brunner, H.-G.; Cederbaum, F. Fungicidal 2-Alkylthio-2-quinolinyloxy-acetamide Derivatives. WO 2009/030469, 12 March 2009.

28. Murphy Kessabi, F.; Quaranta, L.; Beaudegnies, R.; Brunner, H.-G.; Cederbaum, F. Fungicides. WO 2009/087098, 16 July 2009.

29. Buey, R.M.; Calvo, E.; Barasoain, I.; Pineda, O.; Edler, M.C.; Matesanz, R.; Cerezo, G.; Vanderwal, C.D.; Day, B.W.; Sorensen, E.J.; et al. Cyclostreptin binds covalently to microtubule pores and lumenal taxoid binding sites. Nat. Chem. Biol. 2007, 3, 117-125. [CrossRef] [PubMed]

30. Buey, R.M.; Barasoain, I.; Jackson, E.; Meyer, A.; Giannakakou, P.; Paterson, I.; Mooberry, S.; Andreu, J.M.; Diaz, J.F. Microtubule interactions with chemically diverse stabilizing agents: Thermodynamics of binding to the paclitaxel site predicts cytotoxicity. Chem. Biol. 2005, 12, 1269-1279. [CrossRef] [PubMed]

31. Prota, A.E.; Magiera, M.M.; Kuijpers, M.; Bargsten, K.; Frey, D.; Wieser, M.; Jaussi, R.; Hoogenraad, C.C.; Kammerer, R.A.; Janke, C.; et al. Structural basis of tubulin tyrosination by tubulin tyrosine ligase. J. Cell Biol. 2013, 200, 259-270. [CrossRef] [PubMed]

32. Kabsch, W. Xds. Acta Crystallogr. Sect. Biol. Ldots 2010, 66, 125-132. [CrossRef] [PubMed]

33. Adams, P.D.; Afonine, P.V.; Bunkoczi, G.; Chen, V.B.; Echols, N.; Headd, J.J.; Hung, L.-W.; Jain, S.; Kapral, G.J.; Grosse Kunstleve, R.W.; et al. The Phenix software for automated determination of macromolecular structures. Methods 2011, 55, 94-106. [CrossRef] [PubMed]

34. Emsley, P.; Lohkamp, B.; Scott, W.G.; Cowtan, K. Features and development of Coot. Acta Crystallogr. D Biol. Crystallogr. 2010, 66, 486-501. [CrossRef] [PubMed]

35. Chen, V.B.; Arendall, W.B., III; Headd, J.J.; Keedy, D.A.; Immormino, R.M.; Kapral, G.J.; Murray, L.W.; Richardson, J.S.; Richardson, D.C. MolProbity: All-atom structure validation for macromolecular crystallography. Acta Crystallogr. Sect. D Biol. Crystallogr. 2010, 66, 12-21. [CrossRef] [PubMed]

(C) 2017 by the authors. Licensee MDPI, Basel, Switzerland. This article is an open access article distributed under the terms and conditions of the Creative Commons Attribution (CC BY) license (http://creativecommons.org/licenses/by/4.0/). 